\title{
A New Inhibitor to Prevent Hydrate Formation
}

\section{Bazvand M*, Mahmudi S and Shabibi M}

M.Sc of Petroleum Engineering, Oil and Gas Faculty of Sahand University of Technology, Iran

*Corresponding author: Mohammad Bazvand, M.Sc of Petroleum Engineering, Oil and Gas Faculty of Sahand University of Technology, Iran, Tel: +989168768721; Email: mohamad bazvand@yahoo.com

\section{Research Article}

Volume 5 Issue 1

Received Date: January 26, 2021

Published Date: February 18, 2021

DOI: $10.23880 /$ ppej-16000251

\section{Abstract}

Due to the growing demand for energy as well as the depletion of shallow land reservoirs, it sounds more important to utilize deep sea reservoirs. Due to their special conditions, drilling and production of these reservoirs face more problems. The science that helps us avoiding problems during operation is called flow assurance. One of the important issues in flow assurance is to prevent formation of gas hydrates. One of gas hydrates preventing methods is to use of inhibitors. Using of inhibitors is a costeffective and eco-friendly method; so, it is used more nowadays. This paper introduces a new hydrate inhibitor that has been developed from the modification of one of the most widely used inhibitors present in the industry, Poly Vinyl Pyrrolidone, to improve its efficiency. The main structure of the paper is about what is the gas hydrate and its prevention methods. Finally, compare different inhibitors with new one. The results show that hydrate formation time for all polymers is approximately the same, while a half of new inhibitor in compare with amount of others inhibitors causes the same results. This matter shows a double efficiency, and this means a saving of double Polymer consumption.

Keywords: Gas Hydrate; Thermodynamic Inhibitors; Kinetic inhibitors; Poly Vinyl Pirrolidone; Poly Vinyl Caprolactom

\section{Introduction}

Hydrates are referred to inorganic and organic chemicals that contain water. Gases are compounds of solid crystals that are made of gas and water under pressure and temperature above the freezing point of water. In the presence of free water, hydrate is formed when the temperature reaches the temperature of the hydrate formation [1]. The hydrates formation can be partially or totally which causes plug in pipelines. This problem always has been a concern in oil and gas industry, causing serious damage to facilities, especially during marine drilling [2].

In general, to form hydrate, the following conditions must exist:

1. The presence of water or ice

2. The presence of non-polar or slightly polar gas molecules of appropriate size
3. The appropriate pressure and temperature conditions [3].

So we have to control these factors to prevent the formation of hydrates. We will investigate these factors in the following.

- Water control

- Pressure control

- Temperature control [4]

- Chemical method

Chemical method includes addition of inhibitors. This method is the most effective but costliest way to prevent the formation of hydrates inhibitors are widely used in the oil and gas industry to prevent the formation of gas hydrates. Inhibitors are divided into three groups: thermodynamic inhibitors, low dosage inhibitors and dual-function inhibitors [5]. 


\section{Petroleum \& Petrochemical Engineering Journal}

\section{Chemical Inhibitors and their Properties}

Using of chemical inhibitors is one of the common methods to prevent hydrate formation in oil and gas industry. There are several inhibitors which are used. In this section, some of these inhibitors and their properties have been introduced. Then, new inhibitor and its comparison with other inhibitors will be investigated in next section.

\section{Thermodynamic Inhibitors}

These inhibitors influence the hydrates formation thermodynamically. Respectively, by increasing pressure and decreasing temperature of hydrate formation, they do not allow hydrates to form. Adding these substances cause hydrogen bonds of the water molecules get weaken and it forces the hydrate to become unstable while it was being formed at the same temperature and pressure previously. In this condition, formation of a stable hydrate requires higher pressure and lower temperature.

An inhibitor must have the following requirements:

1. Inhibitors should:

A) Be able to lower the formation temperature of the hydrate as low as possible.

B) Completely soluble in water and easy to recover from water.

C) Available and affordable.

2. Inhibitors should not:

A) React with the components in the gas stream and form a solid precipitate.

B) Increase the flammability of the gas.

C) have low viscosity, freezing temperature and vapor pressure

These methods change the thermodynamic equilibrium of hydrate formation and are known as thermodynamic inhibitory methods. Because they change the composition percentage, operating temperature and pressure, the system will be thermodynamically stable and hydrates will not form until the system is stable [1]. Now, we will investigate properties of some usual inhibitors in the following and then compare them with the new inhibitor, Poly Vinyl Pyrrolidone.

\section{Salts}

Macagon showed in 1981 that salts have a direct proportion to number of released ions and an inverse relation to the radius of the ions; so, the best inhibitors are those that release the maximum number of cations with a minimum ion radius. The order of inhibition effect of cations is as follow:

$$
\mathrm{Al}^{3+}>\mathrm{Mg}^{2+}>\mathrm{Ca}^{2+}>\mathrm{Na}^{+}>\mathrm{K}^{+}
$$

Most chlorides, especially $\mathrm{Al} \mathrm{Cl}_{3}, \mathrm{CaCl}_{2}, \mathrm{MgCl}_{2}, \mathrm{KCl}$ and
$\mathrm{NaCl}$ are used as inhibitors. $\mathrm{CaCl}_{2}$ is used more because it is relatively effective and low cost. Sulfates, especially $\mathrm{MgSo}_{4}, \mathrm{NaSo}_{4}$ and $\mathrm{Al}_{2}\left(\mathrm{So}_{4}\right)$ are also good inhibitors. Between phosphates, $\mathrm{Na}_{3} \mathrm{So}_{4}$ is suitable. In addition, ionic radius, number of electric charges and solubility of salts are important. Among anions, chlorides, nitrates and sulfates are the most commonly used. But, salts can cause corrosion as an inhibitor. Salts have higher corrosive properties than alcohols and glycols. $\mathrm{CaCl}_{2}$ has a corrosion of more than 0.02 inches per year at concentrations of about $50 \%$ and low temperatures. Another disadvantage of salts is that some of them are dissolved in the aqueous phase due to heat, but they precipitate when they exposure to cooler areas. In the other words, salts have inefficiency at some conditions, which hydrates are more likely to form [6].

\section{Alcohols}

Alcohol is hydrogen bonded with water by its hydroxyl group. On the other hand, the hydrocarbon atoms of alcohol act similar to natural gas molecules in dealing with water molecules to form clathrates. So, the alcohols have two separate effects on the molecule. Water forms in the formation of clathrates with nonpolar molecules.

Katz, et al. in 1959 showed that by reducing alcohol volatility, their ability to prevent hydrate formation would reduce. The power of alcohols inhibition is given at below:

\section{Methanol> Ethanol>Iso-Propanol}

The good thing about volatility is that volatile alcohols, such as methanol, enter the phase after being evaporated and dissolve in the water, wherever they come across the transmission lines (water and alcohol dissolve in any proportion), and prevent the formation of hydrates. Methanol is the most widely used alcoholic inhibitor due to its price and prevention effect [7].

\section{Glycol}

Glycols, as complexed alcohols, have an additional hydroxylation agent than alcohols; hence, it has the ability to form more hydrogen bonds with water molecules. Glycols (ethylene glycol EG, diethylene glycol DEG, and triethylene glycol TEG) are less volatile than alcohols because of their higher molecular weight. Despite Both glycols and alcohols can be recovered and reused at the end of the pipeline, it's easier to recover and reuse for glycols. EG is more commonly used in liquid hydrocarbons due to its low cost, viscosity and solubility. In non-cryogenic conditions, continuous injection of one glycol (preferably EG) has the economic advantage. On the other hand, injection of alcohol (preferably methanol) is better in cryogenic conditions. 


\section{Petroleum \& Petrochemical Engineering Journal}

In general, methanol has two major advantages over ethylene glycol:

1. With the same mass percentage in the aqueous phase, it has more inhibitory effect

2. It is more Cost-effective

Methanol is non-viscous and non-corrosive. But, due to high vapor pressure, it wastes in the gas phase and its recovery in distillation is relatively costly. So, most of methanol is consumed permanently (without any recovery). It is estimated that $5-8 \%$ of total capital spend to prevent the formation of hydrates. In general, for the above reasons, methanol can be introduced as a better inhibitor than Diethylene glycol [8].

\section{Ammonia}

This inhibitor is very effective (almost twice the methanol inhibitory effect) but it is toxic and corrosive. In addition, it reacts with carbon dioxide over a relatively long time and produces solid carbonate, bicarbonate and ammonium carbamate. These are more problematic than hydrates. Possible reactions have been listed below [9]:

$$
\begin{gathered}
\left.2 \mathrm{NH}_{3}+\mathrm{H}_{2} \mathrm{O}+\mathrm{CO}_{2} \mathrm{NH}_{4}\right)_{2} \mathrm{CO}_{3} \\
\mathrm{NH}_{3}+\mathrm{H}_{2} \mathrm{O}+\mathrm{CO}_{2} \mathrm{NH}_{4} \mathrm{HCO}_{3} \\
2 \mathrm{NH}_{3}+\mathrm{CO}_{2} \mathrm{NH}_{4} \mathrm{CO}_{2} \mathrm{NH}_{2}
\end{gathered}
$$

\section{Low Dosage Hydrate Inhibitors(LDHI)}

Earlier to prevent the formation of hydrates, flowassurance policies would not allow accessibility to hazardous areas. But today, these areas can be reached to reduce costs by using kinetic inhibitors. The problem with traditional thermodynamic inhibitors is to use large amounts of it for prevention. They also require large tanks and equipment for storage and injection, which pollute the environment. It's not easy and affordable to use. Therefore, much attention has been devoted to the development of kinetic inhibitors rather than traditional thermodynamic inhibitors. These inhibitors are used at low concentrations. They cause the formation of hydrates get slow. These materials allow the system to remain stable under thermodynamic conditions; But also, they prevent the growth of hydrate crystals. The amount of used kinetic inhibitor is usually from $0.01 \%$ to $0.5 \%$ and its molecular weight is in range of several thousand to several millions. It is less expensive, easier and more affordable to use than thermodynamic inhibitors. In addition, It reduces the storage volume and transmission volume to a significant extent.

\section{Kinetic Hydrate Inhibitors}

The kinetic inhibitors of hydrate formation postpone the hydrate formation by increasing the time required for hydrate formation to occur in presence of water and hydrocarbons. The length of time that these inhibitors prevent the formation of hydrates is called induction time. This time delay in the formation of hydrates is an opportunity to transport natural gas without the problem of hydration through the pipeline. The presence of kinetic inhibitors depends on many factors such as potency of the inhibitor, type of inhibitor combination, mechanism of action, rate of entry and injection and the driving force behind hydrate formation.

The kinetic inhibitors are mostly polymers and copolymers with chain amide groups such as polyacrylamide or groups with lactam rings (called cyclic amide groups). Lactam rings have an amino group and an ester group. The amine group directly prevents hydrate formation by hydrogen bonding with water molecules; And the ester group also converts to two $\mathrm{OH}$ molecules by hydrolysis in water and get affected by occupation of two water molecules. Higher number of lactam rings used in the polymer causes greater effect. For example, polyvinylpyrrolidone (pvp), which has 5 rings, is generally subcooled at $2-3^{\circ} \mathrm{C}$; But polyvinyl caprolactam (pvcap), which has $8-10^{\circ} \mathrm{C}$ subcooling. They can be used as polymethyl vinyl lactamide and polyvinyl valerolactam. To achieve lower subcooling temperatures, more kinetic inhibitors are needed, which reduces the retention time and the risk of hydrate formation and clogging. So, the design of the formulations of the inhibitors has to consider all aspects due to the limitation of the cooling tolerance by the kinetic inhibitor. In some cases, they get combined to provide some of the temperature reduction through the kinetic inhibitor and the thermodynamic inhibitor.

These materials must have the required temperature tolerance for crossing hot spots. However, some of these polymers do not have high temperature tolerance and this is one of their major problems. For example, pvp has a cloud temperature above $100^{\circ} \mathrm{C}$, but pvcap has a cloud temperature between 30 and $35^{\circ} \mathrm{C}$. Once the temperatures rise above that, the polymers are broken and produce a viscous flow and it breaks down water molecules and hydrogen bonds, which link to polymers. cloud temperature $\left(\mathrm{T}_{\mathrm{cl}}\right)$ of course an important issue, but $\mathrm{T}_{\mathrm{dp}}$ or deposition is more important. As the ionic strength of the water increases, the $\mathrm{T}_{\mathrm{dp}}$ decreases. The subsidence temperature is usually $5-15^{\circ} \mathrm{C}$ higher than the cloud temperature and in some cases this can be extended by specific techniques. Also, they could be compatible with other additives and water salinity.

The mechanism of the kinetic inhibitors is not to reach this critical level before reach the critical limit, but try to disrupt the order of the formed cages after crossing this limit. And as a result, hydrates are destabilizing. Inhibiting polymers alter the microscopic environment around the hydrate crystal and force it to grow between the polymer 


\section{Petroleum \& Petrochemical Engineering Journal}

strands. Hence, they prevent the regular growth of the compressed hydrate crystal. In fact, the created network is asymmetric and without the required robustness and stability. In addition, they prevent gas from entering the crystal and cavities of hydrate by blocking space. In addition, they stop growing of hydrate crystals by absorption control.

The followings are usually considerations to evaluate a kinetic inhibitor:

1. Physical properties including flow capability, viscosity, volatility and density

2. Performance of kinetic inhibitors based on induction time or onset time of hydrate formation, which is one of the most important factors for measuring inhibitory efficiency

3. Compatibility with other additives including anticorrosion inhibitors, mass inhibitors and noninterference

4. Compatibility with compounds in natural gas, condensate and non-deposition in hydrocarbon compounds

5. The amount of formed emulsion; so that, it can easily form stable water or methanol emulsion

6. Suitable injection

7. Environmental aspects [10-14]

\section{Anti Agglomerant Inhibitors}

Anti-agglomerant inhibitors are surfactants. These inhibitors work almost independently of time and under more severe conditions in terms of hydrate formation. However, they are efficient when dispersed in a continuous hydrocarbon liquid environment. In this environment the amount of water phase (water cut) should not exceed 40 to $50 \%$. Therefore, their use in gas transmission lines is not very suitable. In Table 1, the anti-agglomerant and kinetic inhibitors are compared [15]:

\begin{tabular}{|c|c|}
\hline KHI & AA \\
\hline Not affected by water cut & $\begin{array}{c}\text { Affected when water cut } \\
>40 \%\end{array}$ \\
\hline $\begin{array}{c}\text { Work at subcooling up to } \\
10^{\circ} \mathrm{C}\end{array}$ & $\begin{array}{c}\text { Work under more sever } \\
\text { conditions }\end{array}$ \\
\hline Water soluble & Water and oil soluble \\
\hline Slow crystal growth & $\begin{array}{c}\text { Impede hydrate } \\
\text { agglomeration }\end{array}$ \\
\hline Injection at cold point & Injection at turbulent regions \\
\hline
\end{tabular}

Table 1: comparison between AA and KHI.

Although anti-agglomerant inhibitors do not prevent the formation of hydrates, they prevent their accumulation and aggregation. Their mechanism is to block tiny particles of hydrate crystals. They prevent their further growth or the hydrate crystal joining.

Instead of affecting the thermodynamics or growth rate of the crystals, these inhibitors prevent the crystals from adhering and keep them in the state of scattered and suspended particles; Hence, they cannot block the flow path. The mechanism of action of these substances is not yet clear, although it is widely believed that the adsorption of these substances plays a major role. Polymer compositions of this group have two ends with different properties. Hydrophilic heads are absorbed by the hydrate crystal and replaced by the guest molecule while the hydrophobic head remains in space and prevents the water molecules from approaching the hydrate crystal. In addition, the placement of the hydrophobic head in the crystal, due to its different size with the guest molecules, disrupts the crystalline order. These include aromatic sulfonate alkyl, phenyl ethylate alkyl and quaternary ammonium salt with one or two long chains of alkyl ester at the end. These types of inhibitors, such as kinetic inhibitors (KHIs), are injected into the system at very low concentrations (less than 1\%).

\section{Experimental Description}

\section{Apparatus}

A $850 \mathrm{~cm}^{3}$ stainless steel (SS-316) was used for the experimental perform, which can tolerate pressures up to $60 \mathrm{MPa}$. In addition, Circulation of water and inhibitors aqueous solution in the constant-temperature bath with A magnetic stirrer was used to agitate the fluid and solid hydrate phases in the vessel at a speed of $750 \mathrm{rpm}$. The setup also consists of a data acquisition program to log pressure and temperature. We used pure water and methane gas for our experiments.

\section{Procedure}

We washed and dried the cell and performed a leakage test with injection of nitrogen into the cell; Then, we removed all remained gas with vacuum pump. Next, $200 \mathrm{~cm}^{3}$ aqueous solution as a feed was injected into the cell. The pressure adjusted to the desired pressure due to gas injection while temperature was decreasing slowly in a constant rate and the stirrer was rotating at the constant rate of $750 \mathrm{rpm}$.

\section{Results and Discussion}

Among the ways to avoid hydrates, chemical injection is the most efficient method (water removal is virtually impossible, the heating method is very costly, and the pressure reduction method is inconsistent with production policies). These chemical materials include two types of thermodynamic and low-dosage inhibitors, which are 


\section{Petroleum \& Petrochemical Engineering Journal}

low-concentration inhibitors because of their low use, low concentration, reducing costs, lacking equipment such as recycling equipment and environmental hazards. Due to the above reasons, the use of low concentration inhibitors is recommended. Among the thermodynamic inhibitors like salts, alcohols, glycols and ammonia, performance of salts and ammonia are better than other inhibitors; But alcohols and glycols are common to use because of toxicity of ammonia and salts.

Comparison of low-concentration materials also shows that use of kinetic inhibitors is better in high water cut or lack of hydrocarbon liquid phase against in production from deep seas and polar regions with cooling temperatures above $10^{\circ} \mathrm{C}$. Hence, it sounds that using of anti-agglomernt inhibitors would be better. Also, when faced with very high cooling temperatures, simultaneous use of thermodynamic and low-concentration inhibitors would be better. In general, according to the investigations, the most commonly used inhibitory method will be kinetic inhibitor injection. In order to apply low-dose inhibitors, comprehensive information on the system such as fluid retention time in the system, chemical composition of the water, percentage of water cut and other issues such as emulsion production in the pipeline must be considered to select the best inhibitors. Table 2 shows the operational properties of the new inhibitor.

\begin{tabular}{|c|c|c|c|c|c|c|}
\hline Subcooling & $\begin{array}{c}\text { Hydrocarbon } \\
\text { Composition }\end{array}$ & Emulsification & Water Cut & Residence Time & Toxicity & Compatibility \\
\hline Up to $10^{\circ} \mathrm{C}$ & Doesn't matter & Same as other $\mathrm{KHI}_{s}$ & $\begin{array}{c}\text { Doesn't } \\
\text { matter }\end{array}$ & $\begin{array}{c}\text { Same as other } \\
\mathrm{KHI}_{s}\end{array}$ & Non toxic & Same as other $\mathrm{KHI}_{\mathrm{s}}$ \\
\hline
\end{tabular}

Table 2: operational properties of the new inhibitor.

In the following, Tables 3-5 provide a comparison between the properties and performance of the new inhibitor with other thermodynamic and kinetic inhibitors.

\begin{tabular}{|c|c|c|c|c|c|}
\hline & V Cap & VIMA & PVCap & PVP & New polymer \\
\hline$\left.\Delta \mathbf{T}_{\text {sUB }} \mathbf{}^{\mathbf{0}} \mathbf{C}\right)$ & $<6$ & $<8$ & $<10$ & $<4$ & $<10$ \\
\hline $\mathbf{T}_{\mathbf{i}}(\mathbf{m i n})$ & 110 & 115 & 130 & 120 & 100 \\
\hline $\mathbf{T}_{\mathbf{a}}(\mathbf{m i n})$ & 140 & 140 & 180 & 160 & 150 \\
\hline $\mathbf{W}_{\mathbf{t}}$ & 1.0 & 1.0 & 1.0 & 1.0 & 0.5 \\
\hline
\end{tabular}

Table 3: comparison between the new polymer and mostly used THIS.

\begin{tabular}{|c|c|c|c|c|c|}
\hline Flammability & Methanol & EG & DEG & TEG & New polymer \\
\hline NFPA rating & 3 & 1 & 1 & 1 & 0 \\
\hline Flash point & $120 \mathrm{C}$ & $1110 \mathrm{C}$ & $1170 \mathrm{C}$ & $1630 \mathrm{C}$ & $1800 \mathrm{C}$ (melting point) \\
\hline UEL in air & $36.50 \%$ & $15.30 \%$ & $10.60 \%$ & $-\cdots---$ & ----- \\
\hline LEL in air & $6.70 \%$ & $3.20 \%$ & $1.70 \%$ & $-\cdots---$ & $>5000$ \\
\hline LD50 & 9.54 & 4.7 & 14.18 & 17 & Non-toxic \\
\hline Toxicity & Non-toxic & Slightly-toxic & Non-toxic & Non-toxic & 0.5 \\
\hline Wt $\%$ & $60-80$ & $60-80$ & $60-80$ & $60-80$ & \\
\hline
\end{tabular}

Table 4: comparison between the new polymer and mostly used THIS.

\begin{tabular}{|c|c|c|c|c|c|}
\hline Inhibitor & PVP & PV Cap & VIMA & V Cap & New Inhibitor \\
\hline Price(USD/KG) & 310 & 250 & 1000 & 240 & 400 \\
\hline
\end{tabular}

Table 5: cost comparison between the new polymer production and KHIS.

As shown in Table 3, the hydrate formation time for all polymers is approximately the same, while the amount of polymer used for the new inhibitor is half of the other inhibitors. It shows a double efficiency, and this means a saving of double Polymer consumption. The cooling tolerance for the new polymer is also higher than other 


\section{Petroleum \& Petrochemical Engineering Journal}

polymers, which can be one of the most important factors for preferring this inhibitor over others.

As a result of the experiment, we investigated two parameters: induction time and sub cooling which have been shown in following Figure 1:

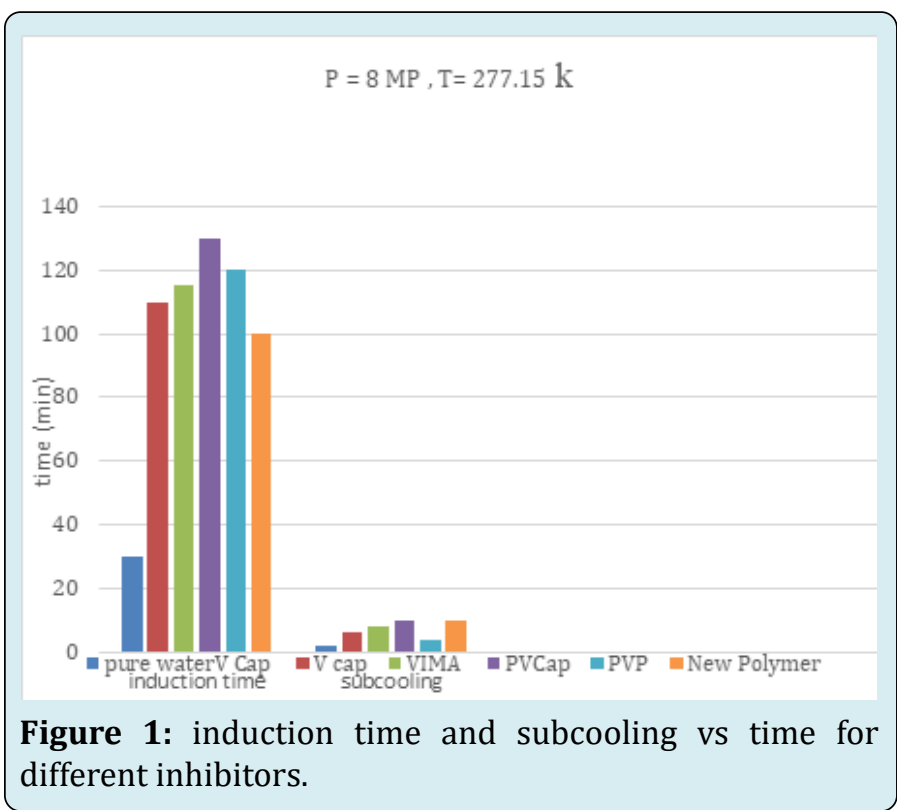

\section{Conclusion}

In this paper the common methods to prevent hydrate formation in petroleum industry, as a major problem, were discussed. Then, the chemical inhibitors were investigated with more details. Finally, the new inhibitor was introduced as a useful and practical method. Overall, according to the studies and comparisons presented in these paper, it can be concluded that the newly synthesized polymer is the best choice to use in the pipeline due to its good performance, low consumption and lower limitations than other inhibitors.

\section{References}

1. Sloan ED (2003) Fundamental Principles and Applications of Natural Gas Hydrates. Nature 426: 353359.

2. PaezJE, Blok R, Vaziri H, Islam MR (2001) Problems in Gas Hydrates: Practical Guidelines for Field Remediation. SPE Latin American and Caribbean Petroleum Engineering Conference, Buenos Aires, Argentina.

3. Makogon YF, Holditch SA, Makogon TY (2007) Natural gas-hydrates. A potential energy source forth $21^{\text {st }}$ Century. Journal of Petroleum Science and Engineering 56(1-3): 14-31.
4. Carroll J (2002) Natural Gas Hydrate a Guide for Engineers. $1^{\text {st }}($ Edn.), Elsevier Science and Technology Books, New York, USA.

5. Zamziali K, Fadhli Hadana R, Bhajan L (2019) Dual function hydrate inhibitor for prevention of hydrate in methane and carbon dioxide system. SPE/IATMI Asia Pacific Oil \& Gas Conference and Exhibition, Bali, Indonesia.

6. Camargo R, Palermo T (2002) Rheological properties of hydrate suspensions in an asphaltenic crude oil. Proceedings of the 4th International Conference on Gas Hydrates, Yokohama, Japan.

7. Benesh ME (1942) The use of gas hydrate in improving the load factor of gas supply systems. US patent No. 2270.016

8. Miller B, Strong EK (1946) hydrate storage of natural gas. American gas association 28(2): 63-67.

9. Hammer S (1939) Gas Hydrate Formation, A further study on their prevention and elimination from natural gas in the pipe line.

10. Notz PK, Bumgardner SB, Schanaman BD, Todd JL (1996) Application of kinetic inhibitors to gas hydrate problems. SPE Prod \& Fac 11(4): 256-260.

11. Fu B, Neff N (2002) Novel low dosage hydrate inhibitors for deep water operation. SPE Prod \& Fac 13(3).

12. Argo CB, Blain RA (1997) Commercial deployment of low dosage hydrate inhibitors $\mathrm{n}$ a southern North Sea. SPE37255.

13. Lovell D, Pakulski M (2002) Hydrate Inhibition in Gas Wells Treated with Two Low-Dosage Hydrate Inhibitors. SPE Gas Technology Symposium, Calgary, Alberta, Canada.

14. Harun AF, Fung GS, Erdogmus M (2008) Experience an AA-LDHI usage for a Deepwater Gulf of Mexico dry-tree oil well. SPE Prod \& Oper 23(1): 100-107.

15. Pickering PF, Edmonds B, Moorwood RAS, Szczepanski R, Watson MJ (2001) Evaluating New Chemicals and Alternatives for Mitigating Hydrates in Oil and Gas Production. IIR Conference, Aberdeen, Scotland. 